\title{
Review: Public service motivation-practical problems, scientific evidence and the role of a research community
}

\section{Wouter Vandenabeele \& Chris Skelcher}

To cite this article: Wouter Vandenabeele \& Chris Skelcher (2015) Review: Public service motivation-practical problems, scientific evidence and the role of a research community, Public Money \& Management, 35:5, 321-327, DOI: 10.1080/09540962.2015.1061165

To link to this article: http://dx.doi.org/10.1080/09540962.2015.1061165

电 Published online: 03 Jul 2015.

Submit your article to this journal $\pi$

Џll Article views: 203

Q View related articles $\triangle$

View Crossmark data \lceil 


\section{Theme: Public service motivation in an international context-taking it one step further}

\section{Review: Public service} motivation-practical problems, scientific evidence and the role of a research community

\section{Wouter Vandenabeele and Chris Skelcher Guest editors}

This review article introduces Public Money E Management's theme papers and articles on public service motivation (PSM). PSM has proven to be a promising road in creating public performance and public value and this theme brings it to an even wider audience, ensuring that policy-makers and those responsible for delivering public services worldwide are aware of the value of PSM research. The article also presents new findings about how best to further PSM research. Keywords: Journal rankings; public administration; public management; public service motivation (PSM); research citations.

The increasing interest in public service motivation (PSM)

Employees are an important ingredient in determining the quality, effectiveness and responsiveness of public services, especially when financial resources are scarce or there are novel challenges to face. How they think and feel about their jobs and working conditions inevitably affects the way they carry out their tasks (Rainey and Steinbauer, 1999). For this reason, many of the reforms implemented in the public sector involve changing the incentives that are believed to influence motivation and thus improve individual and organizational performance. These initiatives include performance management, performance indicators, payment by results, culture change, client-contractor splits, and the creation of business units operating on a trading account basis (Pollitt and Bouckaert, 2011). Such changes are not just matters of organizational restructuring and job redesign, but are profoundly about the normative frameworks that inform public service organizations and the hybrid identities that arise as individuals seek to negotiate the tensions between new and old institutional logics (Skelcher and Smith, 2015).
The concept of public service motivation (PSM), first introduced by Rainey (1982) and later formalized by Perry and Wise (1990), has been shown to improve public performance and create public value (Perry et al., 2010). Evidence demonstrates that the topic has become more popular than ever (Perry and Hondeghem, 2008; Vandenabeele et al., 2014). By April 2015, more than 290 papers had been published in Web of Science-rated journals. This research is also being widely cited, as out of 65 'highly-cited papers' in the Web of Science 'public administration' category, six are on PSM (compared to 18 on climate and ecological policy, 17 on the broad topic of governance including eight on institutions, four on innovation, six on performance management, five on general policy issues and one on methodology) and the only 'hot paper'* in that same category is one on PSM.

In this review article, we reflect on the explanation for this popularity, in particular on the role that the research community and

*Papers that belong to the top $1 \%$ most cited paperscompared to papers published in the same year-in the general category of social sciences are considered by the Web of Science to be 'highly cited', whereas 'hot papers' belong to the recent top $0.1 \%$ papers.
Wouter

Vandenabeele is an assistant professor at Utrecht University and also at

Katholieke

Universiteit Leuven, Belgium.

\section{Chris Skelcher is} Professor of Public Governance,

University of Birmingham, UK. 
special issues or symposia have played in this. Other reasons for the popularity of PSM have been elaborately discussed elsewhere, see Vandenabeele et al. (2014) and Perry et al. (2010). Afterwards, we will identify remaining questions on the topic of PSM. We then introduce briefly how these question have been addressed by the authors in this Public Money $\xi^{\circ}$ Management theme.

\section{The role of developing the PSM research community}

Growth in the popularity of PSM as a focus for scientific research is reflected, apart from the increase in stand-alone papers, in the increasing prevalence of symposia and special issues. The first special issue appeared in Public Policy and Administration (2006). Subsequently, collections of articles appeared in the International Public Management Journal (twice: 2008 and 2010); International Review of Administrative Sciences (2009); Public Administration Review (2010); Review of Public Personnel Administration (2011); International Journal of Public Administration (2012); and Public Administration (2014). At the time of writing (July 2015), we are aware of at least three other initiatives for a symposium or special issue on the topic that are in various stages of progress.

But the popularity of PSM itself is not sufficient to explain the multitude of special issues and symposia. The structure and composition of the research community is also responsible. It is a tightly-knit network of several overlapping groups of researchers who have strong ties with one another. Leaders in each group have sought to increase the visibility of research on the topic and arrange publication opportunities for others, especially junior scholars and newcomers to the field. In the chronology of PSM research, these groups emerged in three waves (Vandenabeele, 2008; Brewer et al., 2012; Perry, 2014).

The first wave occurred just before and after the beginning of the 21 st century. It consisted of mainly US-based research which was developed as a follow-up of the initial conceptual and measurement work by Perry (1996). The second wave of research occurred around 2009 and was a combination of USbased, European and Australasian work, which was mostly centred within US research networks such as the Public Management Research Association (PMRA) and the Academy of Management (AoM), and within European and international networks such as the European Group of Public Administration (EGPA) and the International Research Society of Public
Management (IRSPM). The landmark event of this wave was the international PSM conference in Bloomington, Indiana (US) jointly organized by James Perry and Annie Hondeghem in 2009. This meeting enabled Asian and Australian scholars to meet with their American and European and counterparts, thus stimulating a third wave. This third wave has capitalized to some extent on the two prior waves in terms of its pool of researchers and the dispersion of its research.

Yet more than ever before it has become an international research enterprise. IRSPM, and in particular its panel on PSM, co-organized by one of the editors of this Public Money $\mathcal{E}^{\circ}$ Management theme issue has played an important role in further integrating the various research groups and promoting the exchange of ideas between them. In the past few years, this has become a major platform for PSM research across the globe. It has also encouraged the development of new networks as evidenced by the American Political Science Association, European Academy of Management, and International Institute of Administrative Sciences which have also started to organize separate panels or roundtables on the topic.

In retrospect, the increase in publications has paralleled the creation of scholarly networks and accompanying centrifugal forces that have spread PSM research throughout the academic world. From a scientific perspective, another 'hot topic' within public administration-network governance-teaches us how important the creation and management of networks are for generating performance outputs. Thus, the story of the PSM research community illustrates how a well-networked scientific community can catapult itself forward and increase the quantity and quality of its research output through high-quality discussions that include constructive and substantiated critiques; through norms that promote intellectual freedom steeped in rigorous scientific knowledge; and through ongoing efforts to keep pace with a fastmoving and competitive research arena. The most visible outputs of these networks are publications, which include edited volumes and the aforementioned symposia and special issues published in scholarly journals. It is therefore a combination of the topicality of the subject, the formation of highlyfunctional, interrelated research networks, and the zeal of network leaders that has caused a surge in PSM-related special issues and symposia. 


\section{The impact of PSM research and special issues}

Given these challenges and the associated background of research networks, the question remains whether this strategy of special issues is a good thing for furthering PSM research or whether it is just a convenient strategy-and possibly sub-optimal in the long term. Toanswer the question about the value of special issues on PSM, a small-scale study was conducted.

The study was exploratory in nature, but descriptive and exhaustive in its observations and analyses. The basic model underlying the study included the independent variables of topic (PSM or not), being part of a symposium or special issue on PSM or not, and journal prestige. The dependent variable was the citation score. In order to test the model, we created a dataset that included all articles that were part of a special issue or a symposium on PSM (before 2014). This was achieved by downloading the citation data from the Publish or Perish computer program (Harzing, 2013) (downloaded on 3 September 2013), which is based on Google Scholar data. In order to create a representative variance on the dummy variable that measured inclusion in a symposium or special issue on PSM, we conservatively included the remainder of articles in the volume for each individual journal (so the articles of all issues of the respective journals in the same year the special issue was published were included). These additional articles were then coded on whether or not they addressed the topic of PSM as an extra step to ensure validity and eliminate confounding variables.

The set of 438 articles (descriptive statistics are shown in tables 1 and 2) could therefore be divided into articles that were part of a symposium or special issue on PSM and those that were not. Alternatively, a second variable could distinguish between articles addressing PSM or not. A third variable-the h-index (Hirsch, 2005)—was added to capture the prestige of the journal. This index referred to the h-index of the journal based upon the articles published in the two years preceding the publication of the special issue. As $h$ is the number of articles that is cited at least $\mathrm{h}$ times, it should be interpreted as the number of articles from the previous two years that were cited at least $\mathrm{h}$ times. This is a proxy for the journal's impact in the field, and therefore for its prestige. It is likely that articles in prestigious journals will be cited more often due to their wider distribution or higher prestige. The fourth-and dependent-variable is the
Table 1. Frequencies of dummy variables.

\begin{tabular}{lcc}
\hline & Yes & No \\
\hline PSM articles & 47 & 391 \\
PSM special issues & 42 & 396 \\
\hline
\end{tabular}

Table 2. Means and standard deviations of metric variables.

\begin{tabular}{lll}
\hline & Mean & $S D$ \\
\hline Citations/year & 2.45 & 3.84 \\
H-index of two previous years & 22.16 & 11.38 \\
\hline
\end{tabular}

number of citations. In order to control for the longevity of the article (older articles have a greater probability of being cited than newer ones), we divided the citation score by the years since publication.

As our data are heavily left-censored (many articles never get cited: 128 scored zero citations in this sample), a Tobit-regression is the most suitable method of analysis because it takes into account this type of abnormal distribution (Wooldridge, 2009). The regression estimates therefore cannot be readily interpreted as the effect of the independent variable on the dependent variable but, rather, as a combination of this effect and the probability of being above the limit of zero citations (Wooldridge, 2009). The analysis was performed with SAS 9.2 (QLIM procedure).

Three subsequent hierarchically-built models are presented in table 3 . Model 1 looks at the main effect of journal impact or prestige. This model demonstrates that journal prestige in itself has no independent effect (although positive in direction, the effect is not statistically significant). In model 2, the effect of being part of a symposium or special issue on PSM is added to the model. In this model, both journal impact or prestige and being part of a symposium or special issue on PSM have a positive impact on the citations per year, which may indicate a suppression effect. However, more importantly, the model demonstrates that articles that are part of a symposium or special issue on PSM attract an extra 8.73 citations per year compared with those that are not (with a weight applied to the probability of being cited at least once). Comparing the Akaike Information Criterion (AIC) of models 1 and 2 leads us to the conclusion that model 2 fits the data better than model 1 , and thus model 2 is a better proxy of the reality of being cited. Since the success of articles in PSM symposia and special issues could also be due to PSM's topicality as a research subject, we added a third variable in model 3 which accounts for 
this.* Model 3 indicates that the popularity of PSM as a topic for research indeed accounts for a substantial number of these extra citations (5.41), but at the same time it demonstrates that being part of a symposium or special issue has a positive, independent and statistically significant effect producing 3.42 extra citations per year. Inspection of the AIC of models 2 and 3 demonstrates that model 2 is only 0.0009 times as likely to be the better model, so we conclude that model 3 has the best explanatory power.

The results of this analysis indicate that journal prestige as measured by impact, as well as the topic of PSM and the inclusion in a symposium or special issue on PSM, have independent effects on citations. Insofar as the number of citations is a valid, reliable indicator of impact in the academic community, the analysis demonstrates that the presence of symposia and special issues on PSM is a good thing. This fits with general observations about citation scores of special issue articles as opposed to regular articles, which demonstrate that the former type has a higher citation count than the latter (Conlon et al., 2006). In the case of PSM, one explanation for this finding is that symposia and special issues are more likely to be read in detail by the authors of the other articles, who may work on similar topics. Symposia and special issue articles are therefore more proximal to potential interested users and therefore more likely to be cited. Even in a digital age, people apparently adhere to the structure of journal issues, at least when searching for articles in symposia or special issues rather than stand-alone articles. A second explanation is that this effect is probably reinforced and amplified by the tightly-knitted networks in which PSM scholars typically work. Due to the nature of these networks, the researchers tend to know each other and may be familiar to the gist of the article from prior conference presentations and discussion sessions, making the article even more proximal and therefore more likely to be cited. In sum, due to nature of PSM research networks and the nature of symposia and special issues, articles situated in these outlets are more likely to be cited, increasing the impact of what gets published.

\footnotetext{
*Since articles on PSM and articles included in symposia or special issues on PSM are highly correlated, we calculated the variance inflation factor in a regular OLS model. It did not exceed 10 and tolerance was not below 0.10 , suggesting that multicollinearity was not a big problem.
}

We acknowledge several limitations of this analysis:

- The dataset was a collection of articles that come from journals indexed in the Web of Science. A broader sample of journals might be more representative and allow us to investigate some additional research questions but those questions were mostly beyond the scope of our aims. It should be noted that limiting the selection enabled us to take all symposia and special issues on the topic of PSM into account.

- Additional variables could be added to the dataset, such as whether an article was part of a symposium or special issue on a different topic, and whether the collection of papers came from a network function such as a conference panel or just an open call. These variables would have enabled us to draw broader and more robust conclusions about the role of networks and special publication outlets in general.

- Our analysis was limited to symposia and special issues dealing with PSM research. It would be interesting to conduct a more thorough analysis on how these publications compare with regular ones. However, this, too, was beyond our aims.

- Using other datasets such as Scopus or Web of Science instead of Google Scholar would have excluded some 'grey publications', which are deemed academic but are not peer reviewed. Nevertheless, we relied upon Google Scholar because it is the only citation service that systematically includes books in its indexes, and we felt that books are important publication outlets in the field of public administration and public management.

Finally, we assume that our findings and observations comport with those of many scholars and journal editors in our field. There are some actionable findings: editors can increase a journal's visibility by commissioning symposia and special issues on PSM and other popular topics; and researchers can increase their citation counts by placing their work in such outlets. Moreover, researchers can increase their publication opportunities by embedding themselves in research networks that actively try to organize symposia and special issues. However, the most important finding upon which action should be based is that the combination of research networks and special publication outlets seems to foster building upon prior work and collaboration among researchers-as evidenced by theincreased citation counts that we observed. 
Table 3. Tobit regression on citations per year.

\begin{tabular}{|c|c|c|c|c|c|}
\hline & $\begin{array}{l}\text { Model } 1 \\
\text { SE }\end{array}$ & $\begin{array}{l}\text { Model } 2 \\
\text { SE }\end{array}$ & & $\begin{array}{l}\text { Model } 3 \\
\text { SE }\end{array}$ & \\
\hline H-index of two previous years & $\begin{array}{l}0.03 \\
0.02\end{array}$ & $\begin{array}{l}0.07 \\
0.02\end{array}$ & $\begin{array}{l}* * * \\
0.02\end{array}$ & 0.08 & $* * *$ \\
\hline PSM special issue & & $\begin{array}{l}8.73 \\
0.67\end{array}$ & $* * *$ & $\begin{array}{l}3.42 \\
1.86\end{array}$ & $*$ \\
\hline PSM article & & & & $\begin{array}{l}5.41 \\
1.79\end{array}$ & $* *$ \\
\hline $\mathrm{AIC}$ & 2080 & & 1938 & 1931 & \\
\hline$N$ & 438 & & 438 & 438 & \\
\hline
\end{tabular}

$* p<0.1 ; * * p<0.01 ; * * p<0.001$.

\section{Present knowledge is insufficient: the contribution of this Public Money $\mathrm{E}^{2}$ Management theme}

However, despite the surge in PSM-related research and the increased impact thanks to these special issues, much work remains to be done to provide solid and robust evidence on the relationships that are assumed with outcomes and causes (Moynihan et al., 2013; Vandenabeele et al., 2014). In addition, PSM is typically regarded as a good thing, creating a warm glow of satisfaction in the belief that employees are aligned with a public service organization's values. But little attention has been devoted to the drawbacks of a managerial emphasis on increasing PSM; the work of David Giauque is a notable exception (Giauque et al., 2012; 2013). The scarce robust evidence raises the questions whether public managers should strive to increase their employees' sense of PSM? It might be the case that PSM has a 'dark side', leading to burn-out and disenchantment with the organization and its policies and practices. Combined with the questions that are still open on PSM (Perry et al., 2010; Wright and Grant 2010; Vandenabeele et al., 2014), we think there is need for more evidence on how PSM operates. This Public Money E Management theme issue helps to fill the gap between what we want to know and the existing evidence (for an overview of the present knowledge-base on PSM, see Vandenabeele and Van Loon, 2015). Below, we will describe how we think the various articles in this theme individually contribute to filling the gap.

Public service organizations typically face more demands than they are able to meet with the resources available. In some parts of the world, reductions in public budgets since 2008 have accentuated these problems. How, then, does this affect PSM? Do employees seek to do more with less, or does a less favourable economic environment cause a reduction in their sense of PSM? Using data from the Malaysian public service, Jeannette Taylor and Ranald Taylor's exploratory study (see p. 333 in this issue) indicates a direct relationship between PSM and employees' perception of economic conditions. The worse the perception of economic conditions, the lower the level of reported PSM. In fact, employees were more sensitive to the threat of tangible losses (of job, income etc.) under poor economic conditions than to the gains they might make in stronger economy. Part of the explanation is that losses potentially affect employees' families and relationships more severely than gains. The message for public service managers is that employees' levels of PSM cannot be expected to be sustained-they will not necessarily 'go the extra mile'-when public organizations face hard times.

These issues are reflected in Mark Barrow's debate article (p. 329) on the realities of managing public services in England as they undergoing substantial downsizing. He comments on the 'survivor syndrome' affecting those individuals able to retain their posts after each wave of job reductions, only to face the next prospect of being made redundant. In this situation, he sees the imagination of public servants being tested to the limits and anxiety, guilt and overload reducing their sense of PSM. Radical solutions are required to reduce these negative effects, one being the creation of new organizational entities that offer a sense of hope and renewed motivation to serving the public.

One of the policy drivers for reforms that enhance PSM is to encourage extra-role behaviours that 'go the extra mile'-for example unpaid overtime, making sure the job is finished before leaving work for the day, taking trouble to solve problems that may be beyond the pay 
scale of the individual employee. Maria Koumenta's research on the staff of UK prisons (see p. 341) explores this 'bright side' of PSM, but also investigates the 'dark side' of extrarole behaviour-including absenteeism and non-compliance with organizational procedures. Her research confirms Barrow's observations and finds that 'dark side' behaviours arise where individuals feel the pressures of delivering good public service under challenging conditions. She argues that reducing these effects requires greater attention to PSM values in the recruitment and selection process, so that employees have a greater awareness of the expectations placed on them as a member of the organization under conditions of fiscal or other stress.

Nina Van Loon, Wouter Vandenabeele and Peter Leisink (p. 349) develop these ideasagain on the dark side of PSM-in their study of the relationship between PSM and employee wellbeing in municipal-level public services in the Netherlands. The importance of this research is that it helps explain a contradiction in the literature: that PSM is related to positive outcomes for employees, such as job satisfaction, but at the same time employees with a high level of PSM risk disappointment and frustration due to the role ambiguities, high work pressures and emotional demands of public sector jobs. They propose that a key factor in explaining this relationship is the potential for societal impact (PSI) of a job, and they distinguish between high PSI peoplechanging organizations and low PSI peopleprocessing organizations. Their research finds that employees with high PSM and working in high PSI organizations have a greater propensity to burnout and lower propensity to job satisfaction-employees sacrifice their wellbeing for society's wellbeing.

A group that is frequently involved in delivering societal benefits, yet is largely ignored in the PSM literature, is volunteers (a notable exception is the work by Perry et al., 2008). Steven Parker's (p. 330) debate article argues that PSM policy, practice and research needs to include this large and heterogeneous group. This is increasingly important as modes of public service delivery diverge from the classic public bureaucracy and engage with ideas of co-production, asset transfer to community associations, and citizen-governed services. Parker's qualitative analysis focuses on community leaders, those who mobilize community effort and act as intermediaries between citizens and the state (Munro et al., 2008). He concludes that managers and researchers risk ignoring the biographies of community leaders, instead assuming a stereotypical image. If the PSM of community leaders is to be enhanced, policies and practices should be informed by a more detailed understanding of they paths and experiences that have led to them assuming these positions.

In a diverse world, and with diverse workforces, it is important to consider whether or not these and other scientific findings on PSM can be applied universally. Sung Min Park and Min Young Kim (p. 357) explore this problem through their research on PSM among Korean civil servants working in a Confucian rather than the Weberian system of authority relations. This emphasises a group- and relationship-centred culture within a system of hierarchical deference, rather than one in which individual roles and utility are privileged. They were particularly interested in examining the effects of different types of PSM-rational, norm-based and affective motivation-upon employees' dispositions towards internal and external accountability. Their results show that conventional PSM theory, as developed in the US context, requires adaption for an Asian setting. A more important finding for managers and policy-makers is that employees who have low levels of affective and norm-based PSM could be turned into better performers by increasing the congruence between their role and the organization's mission. Park and Kim identify participatory, bottom-up techniques as appropriate to effect this change, thus giving weight to strategies that open the door for greater employee involvement in reviewing and redesigning organizational practices and procedures.

Ultimately, however, the recruitment and selection of employees is the point at which attention to PSM needs to start, argue Oliver Neumann and Adrian Ritz (p. 365). They propose that one way to improve the personjob fit specification is to see an individual's job selection process as a choice within a threedimensional spatial model comprising extrinsic, enjoyment-based intrinsic and pro-social intrinsic motivations. Using experimental methods, Neumann and Ritz model the choice as a game in which the individual seeks to maximize their motivational utility and show how this could be implemented in the laboratory. This allows for a more refined understanding of the way in which different motivations interact when an individual seeks to match him/herself with a job.

These articles aid us in strengthening the knowledge-base on PSM and to fill some of the 
gaps. The authors are from academia and from the public sector and tell us about the emerging PSM challenges, as well as offering new knowledge on the nature of PSM in an international context. This theme issue tests some of the assumptions inherent in PSM practice and, as a result, offers a more thoughtful and balanced picture, for example focusing on a changing environment. PSM can bring benefits but also cause problems, and in some cases may be counter-productive. The articles here point the way for future research and managerial practice. Our theme issue therefore should be an essential resource for managers, politicians, and trade unions, as they have shared interests in using PSM for the betterment of society, but not at the expense of this society.

\section{References}

Brewer, G. A., Ritz, A. and Vandenabeele, W. (2012), Introduction to a symposium on public service motivation; an international sampling of research. International Journal of Public Administration, 35, 1, pp. 1-4.

Conlon, D. E., Morgeson, F. P., McNamara, G., Wiseman, R. M. and Skilton, P. F. (2006), From the editors: examining the impact and role of special issue and regular journal articles in the field of management. Academy of Management Journal, 49, 5, pp. 857-872.

Giauque, D., Ritz, A., Varone, F. and AnderfuhrenBiget, S. (2012), Resigned but satisfied; the negative impact of public service motivation and red tape on work satisfaction. Public Administration, 90, 1, pp. 175-193.

Giauque, D., Anderfuhren-Biget, S. and Varone, F. (2013), Stress perception in public organizations: expanding the job demands-job resources model by including public service motivation. Review of Public Personnel Administration, 33, 1, pp. 58-83.

Harzing, A. W. (2013), Publish or Perish (www.harzing.com/pop.htm).

Hirsch, J. E. 2005), An index to quantify an individual's scientific research output. Proceedings of the National Academy of Sciences, 46, pp. 1656916572.

Moynihan, D. P., Vandenabeele, W. and BlomHansen, J. (2013), Advancing public service motivation research. Public Money \& Management, 33, 4, pp. 288-289.

Munro, H., Roberts, M. and Skelcher, C. (2008), Partnership governance and democratic effectiveness: community leaders and public managers as dual intermediaries. Public Policy and Administration, 23, 1, pp. 61-79.

Perry, J. L. (1996), Measuring public service motivation: an assessment of construct reliability and validity. Journal of Public Administration Research and Theory, 6, 1, pp. 5-22.

Perry, J. L. (2014), The motivational bases of public service: foundations for a third wave of research. Asia Pacific Journal of Public Administration, 36, pp. 34-47.

Perry, J. L., Brudney, J., Coursey, D. and Littlepage, L. (2008), What drives morally committed citizens? A study of the antecedents of public service motivation. Public Administration Review, 68, 3, pp. 445-458.

Perry, J. L. and Hondeghem, A. (2008), Building theory and empirical evidence about public service motivation.International Public Management Journal, 11, 1, pp. 3-12.

Perry, J. L., Hondeghem, A. and Wise, L. R. (2010), Revisiting the motivational bases of public service: twenty years of research and an agenda for the future. Public Administration Review, 70, 5, pp. 681-690.

Perry, J. L. and Wise, L. R. (1990), The motivational bases of public service.Public Administration Review, 50, 3, pp. 367-373.

Pollitt, C. and Bouckaert, G. (2011), Public Management Reform (Oxford University Press).

Rainey, H. G. (1982), Reward preferences among public and private managers: in search of the public service ethic. American Review of Public Administration, 16, 4, pp. 288-302.

Rainey, H. G. and Steinbauer, P. (1999), Galloping elephants: developing elements of a theory of effective government organizations. Journal of Public Administration Research and Theory, 9, 1, pp. $1-32$.

Skelcher, C. and Smith, S. (2015), Theorising hybridity: institutional logics, complex organizations, and actor identities-the case of nonprofits. Public Administration, 93, 2, pp. 433448.

Vandenabeele, W. (2008), Toward a Public Administration Theory of Public Service Motivation (Faculteit Sociale Wetenschappen, Leuven).

Vandenabeele, W., Ritz, A. and Brewer, G. A. (2014), Past, present and future of public service motivation research. Public Administration, 92, 4, pp. 779-789.

Vandenabeele, W. and Van Loon, N. (2015), Motivating employees using public service. In Perry, J. L. and Christensen, R. K.(Eds), Handbook of Public Administration (Jossey-Bass), pp. 353366.

Wooldridge, J. M. (2009), Introductory Econometrics: A Modern Approach (Cengage Learning).

Wright, B. E. and Grant, A. M. (2010), Unanswered questions about public service motivation: designing research to address key issues of emergence and effects. Public Administration Review, 70, 5, pp. 691-700. 